\title{
Research on the Current Situation of Traditional Sport "Qiang Huapao" for Han Ethnicity of Nuodong Town of Cenxi City of Guangxi Province of China and Its Development Strategy
}

\author{
Lichun Wei \\ Sports School \\ Hechi College \\ Yizhou, Guangxi, China 546300
}

\begin{abstract}
With the name of orient "football", the Qiang Huapao is one of the excellent ethnic traditional sports and is very popular. According to the research on the development situation and measures to the "Qiang Huapao" of Han ethnicity in Nudong town, Cenxi city, Guangxi province, China, and compare it with the one of Sanjiang Dong ethnicity, the results showed that there are differences in its development history, peoples, firecrackers quantity, meanings and shape, and the organizing style. Factors that limit the Qiang Huapao development of Han ethnicity in Nuodong town, Cenxi city are: local policy limit, the influence of the economic reasons, the cultivation of related technical personnel and the lack of supply, this restriction of the equipment used in this activity, etc.. Countermeasures that promote its development are: to strengthen the construction of the space equipment, increase the budget of this project, strengthen the training of coaches and so on.
\end{abstract}

Keywords-Guangxi Province of China; Nuodong Town of Cenxi City; Qiang Huapao; Han ethnicity; current situation and countermeasures

\section{INTRODUCTION}

Qiang Huapao is a popular traditional minority national sports activity, which is known as the eastern "football". According to the research, it has about three or four hundred years history, which is originated in Guangdong at the earliest time, and then spread to the minority areas near by Guizhou, Guangxi and Hunan provinces[1].However in Nuodong Town, Cenxi City located at the east of Guangxi province, this sports is also very popular though most people of this area is Han ethnicity. Nuodong town is located at the northern part of Cenxi City, 19 kilometers away from downtown of CenXi, the

Fund project:1. "Construction and practice research on the characteristic teaching system of the minority traditional sports in colleges and universities in the ethnic minority areas", the important project of reform on education and teaching in Guangxi higher education teaching (2013 jgz154)

2. The research on the plight and innovation development of the traditional sports of Mulam nationality under the modern society; the research project of Guangxi philosophy and social sciences (2013 fty004)

3.The tourism resources development and utilization research of the ethnic sports health keeping culture at longevity area in the northwest of Guangxi province, The special subject for setting up the project of mater degree-conferring unit in 2015 of Hechi Institute. Project No.: 2015LG005. whole town has a total area of 186 square kilometers. It governs 21 villages (streets), a population of 64,500, most of them are Han ethnicity, which is one of three large population towns of CenXi city." CenXi county annals" records: "Cen has people, servants (Zhuang) and slave" [2]. "People" is the general name of han ethnicity that living in the county and the biography minorities at that time. Nuodong town had minority live before the Yuan dynasty, the war of the late Yuan dynasty lead to a large number of Han people in Guangdong, Fujian and other places to move in this place, some of the minority and immigrant Han ethnicity intermarry with each other and gradually assimilated, but most of the minority choose to migrate to the northwest. The Qiang Huapao of Nuodong town, Cenxi city first began in Kangxi 29-year, Qing dynasty, which is one of the most popular activity of "protect the dragon temple" in temple fair. The original holding time is May 13th according to the lunar calendar, after the reform and opening up, it will be held on Jan.13th also according to the lunar calendar, till now, it has developed as a widely popular sports activity. By the research on the Qiang Huapao of Han ethnicity belongs to Nuodong town, CenXi City, we can learn more the development situation in the Han ethnicity belonging to the minority area, try to find the protection strategy for the ancient traditional sports project, promote its good development to make it be inherited better. It has a very important significance for studying the Qiang Huapao activity.

\section{THE DEVELOPMENT SitUATION OF "QIANG HUAPAO"IN THE HAN POPULATED AREAS OF NUODONG TOWN, CENXI City, GuANGXI PROVINCE}

\section{A. The Formation of Qiang Huapao of Han ethnicity in Nuodong Town, Cenxi City, Guangxi Province}

The formation of the Qiang Huapao of Nuodong town, Cenxi City, Guangxi province, China, the earliest can be traced back to the Emperor Kangxi years, Qing dynasty. According to the records "CenXi county annals", the Qiang Huapao of Nuodong is one of the activities of dragon protection temple fair. In Kangxi 29-year, the local squire moved the "Guan Yue Temple" , located at the heart of Nuodong street, to the 
Nuodong new street, and moved to waxy Dong new street, and changed its name to "protect dragon temple", and decided to hold the protection dragon temple on May 13th according to the lunar calendar, the protect the dragon temple is in name of protecting the dragon, but actually, it protect Guan Yu and Yue Fei, in the dozen kilometers of all the temples, it is the only one temple of irreverence deities. A grand temple fair of every year is a way to celebrate the harvest festival and commemorate Guan $\mathrm{Yu}$ and Yue Fei, attracting business and social people, children, old men, women will come and join in it. Early years of the Qianlong, negotiated by the country gentry and literati, met and discussed to fire ten according to the 10 mahonia of Guan $\mathrm{Yu}$, and which is inherited till now. In legend, the firecracker is a symbol of auspicious well-being, peaceful country and safe people, good harvest. The one who get the firecrackers can be added luck and life-time, people are wealthy, and everything is complete. Now there is a "blasting slope" at Nuodong street, it is the "competition location" of Qiang Huapao activity at that time. In cultural revolution period, due to dispel the influence of feudal superstition, temple fair, dragon temple activities was forced to cancel, this activity was also suspended, the original shooting location was used for residential land. After the reform and opening up, grasp to carry forward the national spirit of sports, the local people led back this activity under the lead of Mr. Qun Chen and set up the fireworks association in 1988, it will be responsible for all matters relating to this activity.

\section{B. The Feature of Qiang Huapao of Han Ethnicity of} Nuodong Town, Cenxi City, Guangxi Province, China

Qiang Huapao is an original traditional activity with strong local characteristics, it is the test of wisdom and courage, also the luck to try, and the embodiment for the unity and the concerted action and success, it is a symbol of good fortune as one wishes. It has become a sacred and auspicious incarnate in the minds of Nuodong people. By visiting the people nearby the Protect Dragon Temple located in Nuodong street and interviewing the chairman of firecrackers of Nuodong council belongs to Nuodong town, Cenxi city, we knew that the firecrackers can be divided into five parts - firecracker head, firecracker body, firecracker axis, firecracker neck and firecrack guts, its head and body is connected by its axis to make the firecrackers shelves, placed the firecracker neck in its head, which is made of iron cylinder and can be placed the gunpowder inside. Before the game, place the firecracker gallbladder in its neck, after the host announced the begin of the game, light the firecrackers fuses connecting with the neck, then the explosion gunpowder will eject its gallbladder to the air. In general, the "Qiang Huapao" actually refers to contesting for the cavity of firecracker. It is an iron ring with about $5 \mathrm{~cm}$ diameter and wrapped by red cloth. The firecracker head and body of Qiang Huapao of Han ethnicity in Nuodong town, Cenxi City is made by the local old technicians with bamboo cane and color paper, which is very complex, it has delicate appearance and extremely local characteristics. After hundreds of years of inheritance and development, the firecracker has become as a comprehensive mass cultural activity which evolve the float parade, play Niulang and Zhinv, watch cantonese opera, lion dance, dragon dance, ChunNiu dance, clime a mountain with swords and other activities.

\section{Present Situation of Qiang Huapao of Han Ethnicity in Nuodong Town, Cenxi City, Guangxi Province, China}

Qiang Huapao is a traditional folk activity, popular within the territory of Cenxi city, this kind of activity in Nuodong town is the most distinctive one .As a large crowd folk activity, it attracts public attention by its unique form, strong local color, rich cultural connotation and spontaneous, voluntary participation and the spirit of struggle. Since it was founded in 1998, Nuodong fireworks association in Cenxi city has successfully held for more than ten session of this activity, the Qiang Huapao in Nuodong of Han ethnicity is still using the traditional way of the game. There is no clear limit to the size of the area and the number of people to participate in the competition.Now, the Qiang Huapao in Nuodong town, CenXi city has developed into a mass cultural activities including play of Qiang Huapao, parade floats, play about Niulang and Zhinv, Chunniu dance and so on, each session will attract people to watch from the villages and towns. In recent years, under the promotion of the development by this association, the Qiang Huapao of Nuodong town, CenXi city had been successively listed as the important project of the non-material cultural heritage by its leadership team of Cenxi city in 2006; in 2007, Wuzhou government of Guangxi Province listed this activity into the "China the first batch of intangible cultural heritage list"; in 2010, it was listed in the third batch of regional intangible cultural heritage list. Qiang Huapao organized by its association had won the second prize in whole district in the grand meeting held in Yangshuo on Mar.3rd.

\section{THE DIFFERENCE OF QIANG HUAPAO BETWEEN THE HAN ETHNICITY AND DONG ETHNICITY IN NUODONG TOWN, CenXi City, Guangxi Province, China}

Qiang Huapao is a traditional sports activity with strong ethnic characteristics, which is not only popular in Dong, Zhuang and other minority nationalities, but also has been widely circulated in the Han areas. Comparing the Qiang Huapao of Han ethnicity with the one of Sanjiang Dong ethnicity, we can find can find the similarities and differences between them.

\section{A. Differences}

1) Different development history and ethnicity: Qiang Huapao of Han ethnicity in Nuodong town, CenXi city is one of the temple activities in the dragon protection temple which is enshrined the "emperor of Guan Yu", it is to remember the loyalty of Guan $\mathrm{Yu}$, and ten firecrackers will be set off on May 13 according to the lunar calendar. It is begun in the 29th year of Kangxi period (AD 1960), and has 300 years' history [3].About the origin of Qiang Huapao of Dong ethnicity, it can be roughly classified into three kinds of views: firstly, from the ancient local legend, a legend story. Second, origin from the local religious ritual activities, the worship of a deity and held a ceremony, it has strong local superstition color. Thirdly, in order to gather the crowd, active his business, the predecessors' ancestors businessman hold an activity funding by them. According to "Sanjiang dong autonomous county annals" records: this is one of the activity of Sanjiang town 
temple fair, in Xianfeng period of Qing dynasty (1851-1861), to sacrifice the local "two holy Lord" and Wusheng palace (the Guan Yu temple), this kind of activity will be held on Mar.3rd according to the lunar calendar, the local people call it as "out of window". Then it gradually spread in Sanjiang Dong autonomous county [4].

2) Difference on firecrackers quality and its meaning: There are ten firecrackers in the Qiang Huapao activity of Nuodong town, Cenxi city, each firecracker will be tied one iron ring as a symbol of happiness on the iron ring, which outside is covered by red cloth, and then put in large firecrackers, the iron ring rush in the air, and fall, then the people scramble, the one who get it first will win. The first, second and the seventh firecracker are taken as heavy firecracker, they symbolizes prosperity, adding rich, money and treasures. In this activity, most people intensely scramble these three firecrackers. The other seven means everything goes well, although these seven are not heavy firecracker, but its intensity for getting it is similar with the first, second and seven ones; In legend, the Qiang Huapao of Dong ethnicity is origin from the reward ceremony in ancient temple fair, the temple set off 3 firecrackers, the first of it means the good weather for crops, human and animal are peaceful, the second is prosperous, the third means a thriving business. Everyone will attract a lot of people competing for getting it, which also reflects the yearning of people and desire for a better life.

3) Difference appearance: The firecrackers used by Han ethnicity, in Nuodong town, Cenxi city, in its Qiang Huapao activity is a iron ring with about $5 \mathrm{~cm}$ diameters and covered by red cloth. Put the ring on the firecracker neck, and then put the neck in the firecracker shelf with the width of $88 \mathrm{~cm}$, $166 \mathrm{~cm}$ firecracker head and $154 \mathrm{~cm}$ firecracker body. Set off the lead that connected with the firecracker neck, the explosion powder will rush the firecracker gallbladder to the air and the people will begin to scramble it when the ring is falling; The firecracker ejector used in Sanjiang firecrackers fireworks festival is made of firecracker shelf and nitrate buckets, people scramble the firecrackers ring placed on nitrate buckets, the firecrackers ring is usually made of iron rings, bamboo ring made of bamboo sticks, or rattan bamboo circle, about $8 \mathrm{~cm}$ in diam., covered by silk till only two fingers can put into iron circle, then put it on a iron mill full filled with gunpowder with the height $15 \mathrm{~cm}$; after the host announced the beginning, put the fireworks on the cylinder verge of iron milling, set off the gunpowder, and then the firecrackers will be ejected to the air, people begin to scramble the ring when it is falling [5].

4) Different organization style: In 1998, Nuodong town, Cenxi city founded the Nuodong fireworks association, and decide that each session of this activity will be organized by this association. In order to attract more viewers to participate in it, Nuodong fireworks association will organize other activities during the fireworks. Such as play movies, play Niulang and Zhinv, parade floats, lion dance, dragon dance, and so on, the scene is very spectacle; The organization way of Qiang Huapao for Sanjiang Dong ethnicity is that the one who get the first firecrackers, this event in the coming year will be hosted by the people that live in the same village of the winner, the host village will prepare some same prizes as the last year, such as one of the village that got the first firecracker last year and got a braised pig as the prize, then the prize in this year should also include one braised pig, these prizes are called " give back color". If any village can consecutively win this activity for two years or more than two years, it means that the village will get good harvest for several years, at the same time, the village will also become as one place that all Dong ethnicity girls are looking forward to [6].

\section{B. Same Features}

1) The same requirements to competition places and participation people quantity: The Qiang Huapao activity of the Han ethnicity in Nuodong town, Cenxi city and the traditional Qiang Huapao of Sanjiang Dong ethnicity have low demands on the field. It can be hills, river banks, fields, there is no limit to the number of people, and the audience can be involved in the game at any time. But with the development of The Times, the rules of the game have been changed at a large degree. Such as the requirements to this game site should be one round ground with 100-150 meters diameter. In name, this game is held by the team, but there is no limit to the number of the teams and people. One person can be as one team, and also ten persons can be one team.

2) All Qiang Huapao activities include the yearn for good life of people: Whether for the Qiang Huapao activity of Han ethnicity in Nuodong town, Cenxi city or the one in Sanjiang Dong ethnicity, every firecracker in this game will be added one meaning of a good fortune by people. Such as: the first firecracker in Nuodong town, CenXi city means the good fortune as one wishes, the one in Sanjiang Dong ethnicity means good weather for the crops. It is inherited in the history of hundreds of years in Qiang Huapao activity, although it has a little color of feudal superstition, it reflects the people are looking forward the good things and happy life, and is the anchorage of the spiritual world.

\section{THE RESTRICTING FACTORS FOR THE DEVELOPMENT OF Qiang HuAPAO ACTIVITY IN NUODONG TOWn, CENXI CiTy, GuANGXi Province, ChInA}

\section{A. Less Attention from Local Policy}

Although this activity have been listed in the non-material cultural heritage list in CenXi city, Wuzhou City and autonomous regions, but because the government does not pay enough attention to the development of it, and there is no relevant policies to support its development. Now Cenxi city is a Han populated area, so there is no opportunity to take part in the Guangxi minority games and even the ones in the whole country, which limit mutual communication on Qiang Huapao between Han and minority nationalities, and also hinder the development of it in Han ethnicity. 


\section{B. Influence from Economy Reason}

Any sports development cannot have the support of the economic foundation. It is same to the Qiang Huapao activity in Nuodong town, CenXi city, a region's level of economic development determines the funds needed for the construction of sports in this area and facilities maintenance, and also decides the developing market and requirements of the national sports industry .For a long time, the industrial structure of this activity in Nuodong town, Cenxi city is in a relatively primitive state, its own resources transformation ability is very weak. It will be hard to obtain a good development without the fund support.

\section{Lack of the Training and Supply for the Relevant Technicians}

Reserve talented person is the foundation of a sports breeding, and the coach is the guarantee of its development. If you have no hand you cannot make a fist. If there is not enough reserve talented person, the smartest coach also can not know how to start. At the same time, to find the swift horse also need a good bole, a good coach can make those potential talents to be as real talents at an early date. In Nuodong town, CenXi city, the reserve talented person is under the condition of shrinking, the relevant departments should take advantage of existing reserve talented person and the coaches to develop the potential market, it is one of the important guarantees for its prospect.

\section{Limit on Equipment Needed by Qiang Huapao Activity}

Due to the limits of regional factors, there is no sales market for this equipment in many areas, so many businessmen do not produce this kind of equipment, according to the introduction of Mr. Qunsheng Chen, the chairman of the fireworks association, now, the equipment used in Qiang Huapao in Nuodong town, CenXi city still follow the traditional way, which is made by the technicians who make the firecrackers, so its safety, practicality is not high, and the young people are not willing to learn this art, the craftsmen who currently engaged in the activities are older, then this technique will face a crisis of lost work.

\section{DEVELOPMENT MEASURES FOR QIANG HUAPAO ACTIVITY OF HAN ETHNICITY IN NUODONG TOWN, CENXI City, GuangXi Province, China}

\section{A. Promote the Sites Construction and Production of Equipment}

Line out the space for carrying out the Qiang Huapao activity in Nuodong town, Cenxi city, keep the traditional sites and rules of this activity and at the same time, introduce site standard and game rules used in the national minority games of Qiang Huapao, which can keep the competition way of the traditional style of this game, at the same time, and can carry out the modern Qiang Huapao activity according to the site standard and rules of national games. Introduce the enterprise specialized in these equipments on the aspects of production, manufacture and sale. Reform the equipment used in Qiang Huapao activity, improve its safety, beauty and practical. In the manufacture and sale of this device in the enterprise, the modern technology and equipment is introduced in this reform, making the instruments for Qiang Huapao is safer, more beautiful and practical. For this sports equipment manufacturing enterprises, the government can give policy and financial support.

\section{B. Develop the National Sports Travel Projects, Add Fund for the Qiang Huapao Activity}

With the development of itself continuously, this movement is not only the region folk festivals in Zhuang area, and the competition project in the national minority games, on this basis, it has gradually developed into a rare region unique ethnic tourism resources in Guangxi province[7].Carry out the ethnic tourism project with the subject of Qiang Huapao in Nuodong town, take reasonable effective means, vigorously carry forward the traditional culture, to make the essence of culture to live on and let more people know and like the national traditional sports. And reasonable effective tourism development is the good way of inheritance and protection for the traditional culture, so the role of the tourism development is a great[8].In the development of sports tourism project, due to its tourism features, from the present situation of this national traditional activity, its competition system and safety measures, etc, still have a series of problems[9].To solve these problems, we should combine tradition and modern, to promote the modern transformation of traditional Qiang Huapao activity.

\section{Enhance the Training and Communication to the Relevant Technicians}

Organize the talent and technology exchange conference, strengthen the communication between Qiang Huapao activities in Nuodong town and other minorities, to form the integration development model of the Han ethnicity and minority. Enhance the cultivation of the technical personnel and coaches, strengthen the cultivation of the talent resources, the exchange of competition, the exchange of temporary transfer, the exchange of talent training, the exchange of talent transfer and so on. Carry out this training course, add this to the sports event in the middle and primary school in Cenxi city, and hold a regular tournament of Qiang Huapao activity. Make practice by competition, train excellent talent and promote the technology level.

\section{Support from the Government Policy}

Qiang Huapao activity is an excellent ethnic sports with long history, this activity of Han ethnicity in Nuodong town,Cenxi city and the one in Sanjiang Dong ethnicity should communicate with each other, find the other's advantages to promote and develop itself. Introduce the Qiang Huapao activity to the teaching courses in the school sports class, promote "Qiang Huapao"- this traditional ethnic sports. Lead by the government, connect with the activity of "Qiang Huapao", and combine the economy and business activity, cultural activity and folkways activity together to improve the development of local economy by Qiang Huapao activity. 


\section{E. Set Up the Origination to Manage the Development and Promotion of Qiang Huapao}

Take Nuodong town as key place to set up the management association for "Qiang Huapao", which is used to solve the problems in the process of development and management of "Qiang Huapao" activity. Contact with the Qiang Huapao organizations in all places and peoples to set up one organization that can improve the Qiang Huapao level and promote its development, generally arrange the Qiang Huapao activity, and organize this kind of organizations in all places and peoples to do discussion, research and communication. Arrange, clarify, record these document and results gotten from the general inspection and research results, continuously inspect and research them carefully to find the production, formation and development history and embodied value of the Qiang Huapao, make the book and document on Qiang Huapao.

\section{F. Keep and Protect the Inheriting and Developing Space of the Traditional Qiang Huapao}

Qiang Huapao is an important part of ethnic sports, and as the link for ethnic material and spirit, the ethnic tradition sports is actively inherited by each people in the long social history development[10].Qiang Huapao activity in Nuodong town, Cenxi city is a popular traditional sport in that area. Thus, when we introduce the modern sports system to form this activity, we should not remember to protect its tradition, and provide development space for it, so that the tradition of it is not lost and the modern system can be improved. Traditional way of this activity is the treasure of the Chinese national sport accumulated in the hundreds of years' inheritance.

\section{REFERENCES}

[1] Lichun Wei, Guangming Ling. Traditional minority national sports course[M]. Beijing: People's Education Press, 2008,9:50-61.

[2] Mengyao He. CenXi county annals[M], 1739.

[3] Cenxi county annals office.Cenxi county annals.literature and art piece[M], 1992, 12: 75-76.

[4] Hua Zhou. Research on the cultural features of "Qiang Huapao"- take Qiang Huapao activity in Sanjiang Dong ethnicity, Guangxi province as example[J].Helongjiang local Chronicles,2009, (14) : 89-90.

[5] Qiang Huapao[J].Ethnic Today.2011, (1) : 27-28.

[6] Xueting Guan, Zhuping Liang. Qiang Huapao activity of Dong ethnicity[J].Sports people history, 1985, 6: 33-34.

[7] Ren Fang.Travel development conception on Qiang Huapao[J]. Journal of Guangxi University for Nationalities, 2005, (S2) : 139-140.

[8] Zejiang He.Research on the current situation and development prospect of Qiang Huapao[J]. Journal of Jilin Sports college,2004, (20) : 124125.

[9] Jingsheng Bin, Xinping Jiang, Jinyu Fan. Analysis on the development of the folk athletic culture in ethnic traditional festivals[J].Journal of Jilin Sports college,2010, (4) : 129-134.

[10] Yong Jiang, Tianyi Wang. Discussion on the social value and realistic meaning of the "Qiang Huapao"in the traditional sports of Zhuang ethnicity[J].Journal of Taiyuan Career College, 2010, (1) : 164-165.

[11] Hansheng Huang.Scientific research on sports science[M].Beijing: High education press, $2006,7$. 